\title{
ESTIMATION OF IONOSPHERIC DELAY INFLUENCE ON THE EFFICIENCY OF PRECISE POSITIONING OF MULTI-GNSS OBSERVATIONS
}

\author{
Alina Khoptar, Stepan Savchuk \\ Lviv Polytechnic National University
}

\begin{abstract}
Currently, Global Navigation Satellite Systems (GNSS) are developing at a fairly rapid pace. Over the last years US GPS and Russian GLONASS were modernizing, whilst new systems like European Galileo and Chinese BDS are launched. The modernizations of the existing and the deployment of new GNSS made a whole range of new signals available to the users, and create a new concept - multi-GNSS. Ionospheric delay is one of the major error sources in multi-GNSS observations. At present, GNSS users usually eliminate the influence of ionospheric delay of the first order items by dual-frequency ionosphere-free combinations. But there is still residual ionospheric delay error of higher orders. In this paper we present four different processing scenarios to exclude the higher orders ionospheric delay effects on multi-GNSS Precise Point Positioning (PPP) performance, including: "only GPS" and "GPS+GLONASS+Galileo+BDS" - without/with eliminating ionospheric delay error of higher orders. Dataset collected from one GNSS station BOR1 (Borowiec, Poland) over almost two years provided by multi-GNSS experiment (MGEX) were used for dual-frequency PPP tests with one- and quadconstellation signals. For the second pair of scenarios were used a IONosphere map EXchange format (IONEX) that supports the exchange of 2- and 3-dimensional TEC maps given in a geographic grid. Numeric experiments show that, the results of different pairs of scenarios differ at the submillimeter level. The results also show that the multi-GNSS processing are better than those based on "only GPS".

Keywords: Global Navigation Satellite Systems (GNSS), multi-GNSS, Precise Point Positioning (PPP), ionospheric delay.
\end{abstract}

\section{Introduction}

With the fairly rapid pace of Global Navigation Satellite Systems (GNSS) development, its applications in high-precision GNSS geodetic fields, the positioning accuracy has been noticed more and more. With the modernization of US GPS (Global Positioning System) and Russian GLONASS (GLObal NAvigation Satellite System), and newly developed European Galileo and Chinese BDS (BeiDou Navigation Satellite System), users had been able to receive an observations data from different satellite constellations in a whole range of new GNSS signals that formed new term - multiGNSS.

The ionosphere can be determined as the part of the upper atmosphere, where the density of free electrons and ions is so high that influences the electromagnetic waves propagation (Hargreaves, 1992). The ionosphere can cause a delay in observations, when GNSS signals passing from the satellite to the receiver. As follows, the ionospheric delay is one of the major error sources of GNSS observations, and, accordingly, multi-GNSS. The ionospheric delay estimations with using a prior ionosphere model have the potential to improve positioning productivity for more applications ( $\mathrm{Gu}$ et al., 2015; Lou et al., 2016).

The first-order of ionospheric effect can be corrected by using linear combinations of GNSS observations that are free from the influence of the ionosphere (Ionosphere-Free, IF ) (Odijk, 2003; Seeber, 2008). In recent years, Precise Point Positioning (PPP) method are increasingly being used for high-precision processing of GNSS observations data, including processing data based on multi-GNSS observations (Savchuk, Khoptar, 2019). The concept of PPP is based on single-receiver point positioning using GNSS measurements along with precise orbit and clock information and additional error modeling and dual-frequency code and phase measurement filtering (Zumberge et al., 1997). It mainly associated with the software package GIPSY-OASIS, or rather, its improved version - GipsyX (Official web-site of GIPSY-OASIS software package), that was developed by Jet Propulsion Laboratory (JPL) of California Technical Institute. With this software package observed signals processed using the $I F$-combination of L1 and L2 signals. But notwithstanding, that the first-order of ionospheric effect corrects with $I F$-combination, there are residual ionospheric delay errors which are caused by the second- and third-order of ionospheric effect (Marques et al., 2012). Thus, for improving the positioning accuracy, it is necessary to exclude the higher-orders ionospheric effects on multi-GNSS observations. 
It was investigated the four different multi-GNSS data processing scenarios in PPP-mode with helping GipsyX software package for GNSS station BOR1 (Borowiec, Poland) to exclude the higher orders ionospheric delay effects, including: "only GPS" and GPS+GLONASS+Galileo+BDS" - without eliminating ionospheric delay error of higher orders; "only GPS" and "GPS+GLONASS+Galileo+BDS" - with eliminating ionospheric delay error of higher orders.

\section{Methodology of research and materials}

In multi-GNSS data processing, with considering the higher-order ionospheric delay (Elsobeiey, ElRabbany, 2012), the $I F$-combination of each GNSS separately for code (pseudo-distance $P$ ) and phase (pseudo-distance $L$ ) observations between GNSS station $r$ and corresponding satellite $s$ (conventionally marked as $G$-GPS, $R$-GLONASS, $E$ - Galileo and $C-\mathrm{BDS}$ ), can be formulated as (Savchuk, Khoptar, 2019):

$$
\begin{gathered}
\left\{\begin{array}{l}
P_{r}^{G}=\rho_{r}^{G}+c\left(t_{r}-t^{G}\right)+c\left(b_{r}-b^{G}\right)+T+\frac{p}{f_{i}^{2}}+\frac{q}{f_{i}^{3}}+\frac{t}{f_{i}^{4}}+e_{r}^{G} \\
P_{r}^{R}=\rho_{r}^{R}+c\left(t_{r}-t^{R}\right)+c\left(b_{r}-b^{R}\right)+T+\frac{p}{f_{i}^{2}}+\frac{q}{f_{i}^{3}}+\frac{t}{f_{i}^{4}}+e_{r}^{R} \\
P_{r}^{E}=\rho_{r}^{E}+c\left(t_{r}-t^{E}\right)+c\left(b_{r}-b^{E}\right)+T+\frac{p}{f_{i}^{2}}+\frac{q}{f_{i}^{3}}+\frac{t}{f_{i}^{4}}+e_{r}^{E} \\
P_{r}^{C}=\rho_{r}^{C}+c\left(t_{r}-t^{C}\right)+c\left(b_{r}-b^{C}\right)+T+\frac{p}{f_{i}^{2}}+\frac{q}{f_{i}^{3}}+\frac{t}{f_{i}^{4}}+e_{r}^{C}
\end{array}\right. \\
\left\{\begin{array}{l}
L_{r}^{G}=\rho_{r}^{G}+c\left(t_{r}-t^{G}\right)+\lambda^{G}\left(N_{r}^{G}+B_{r}-B^{G}\right)+T+\frac{p}{f_{i}^{2}}+\frac{q}{2 f_{i}^{3}}+\frac{t}{3 f_{i}^{4}}+e_{r}^{G} \\
L_{r}^{R}=\rho_{r}^{R}+c\left(t_{r}-t^{R}\right)+\lambda^{R}\left(N_{r}^{R}+B_{r}-B^{R}\right)+T+\frac{p}{f_{i}^{2}}+\frac{q}{f_{i}^{3}}+\frac{t}{f_{i}^{4}}+e_{r}^{R} \\
L_{r}^{E}=\rho_{r}^{E}+c\left(t_{r}-t^{E}\right)+\lambda^{E}\left(N_{r}^{E}+B_{r}-B^{E}\right)+T+\frac{p}{f_{i}^{2}}+\frac{q}{f_{i}^{3}}+\frac{t}{f_{i}^{4}}+e_{r}^{E} \\
L_{r}^{C}=\rho_{r}^{C}+c\left(t_{r}-t^{C}\right)+\lambda^{C}\left(N_{r}^{C}+B_{r}-B^{C}\right)+T+\frac{p}{f_{i}^{2}}+\frac{q}{f_{i}^{3}}+\frac{t}{f_{i}^{4}}+e_{r}^{C}
\end{array}\right.
\end{gathered}
$$

where $P_{r}^{S}$ - code pseudo-distances (unit: $\mathrm{m}$ ); $L_{r}^{S}$ - carrier phase pseudo-distances (unit: $\mathrm{m}$ ); $\rho_{r}^{S}$ geometric distance between GNSS station and satellite (unit: $\mathrm{m}$ ); $c$ - speed of light in vacuum (unit: $\mathrm{m} / \mathrm{s}$ ); $t_{r}$ - receiver clock errors (unit: $\mathrm{s}$ ); $t^{S}$ - satellite clock errors (unit: s); $\lambda^{S}$ - wavelength of the carrier phase (unit: m); $N_{r}^{S}$ - integer carrier-phase ambiguity (unit: cycle); $b_{r}$ and $b^{S}$ - delays in equipment for code observations (unit: $\mathrm{m}$ ); $B_{r}$ and $B^{S}$ - delays in equipment for phase observations (unit: $\mathrm{m}$ ); $e_{r}^{s}$ - disregarded effects (noise of receiver, multiply beam, etc.), $T$ - tropospheric delay (unit: $\mathrm{m}$ ); $f_{i}$ - frequencies with the dependent terms (unit: $\mathrm{Hz}$ ); $p$ - total electron content integrated along the line of sight $(S T E C), q$ - second-order ionospheric effect, $t$ - third-order ionospheric effect.

According to (Bassiri, Hajj, 1993) $p, q$ and $t$ can be given as:

$$
\begin{gathered}
p=40.3 \int N e d l=40.3 \text { STEC } \\
q=7527 c \int N e B \cos \theta d l \approx 2.2566 \times 10^{12} B \cos \text { BSTEC } \\
t=2437 \int N e^{2} d l+4.74 \times 10^{22} \int N e B^{2}\left(1+\cos ^{2} \theta\right) d l \approx 1602.749 N e_{\max } S T E C
\end{gathered}
$$

where $N e$ - electron density (unit: electrons $/ \mathrm{m}^{3}$ ), STEC - slant total electron content, $B$ - magnetic field at the at the ionospheric pierce point, $\theta$ - angle between the magnetic field and the propagation 
direction, being the integral performed over the line of sight, $N e_{\max }-$ maximum electron density at the height of the ionospheric layer.

It is known, that the higher-order ionospheric delay depends on the STEC along the line of sight, magnetic field parameters at the ionospheric pierce point, and the angle between the magnetic field and the direction of signal propagation. STEC values may be obtained from agencies such as the International GNSS Service (IGS), Centre for Orbit Determination in Europe (CODE), Jet Propulsion Laboratory (JPL), European Space Agency (ESA) and others, that use different approaches to compute the global ionospheric model (Feltens, Schaer, 1998). These agencies produce global ionospheric maps (GIMs) in the ionospheric exchange (IONEX) format (Schaer et al., 1998). For example, CODE GIM (CODG) comes from processing double-differenced carrier phase data and TEC parameterization using Spherical Harmonics Expansion "SHE" functions and Bernese software (Schaer, 1999). Thus, for excluding the higher-order ionospheric delay effects on multi-GNSS observations data processing, in this study we had using IONEX files from CODE.

\section{Discussions and results}

To investigate the effect of higher-order ionospheric delay on multi-GNSS data processing, GipsyX software package was used. For data processing, we have selected data from multi-GNSS station BOR1 located in Borowiec, Poland. The necessary for observations processing data had been downloaded from the Multi-GNSS-Experiment (MGEX) website for the period from DOY281 of 2017 (October 08, 2017) to DOY161 of 2019 (June10, 2019). This choice was depended on the data presence of multi-GNSS observations in RINEX version 3 and MGEX-products from CODE. Therefore, precise orbit, clock, antenna phase center correction and other products, including IONEX files, were downloaded from the CODE analysis center. Data observations processing occurred at four scenarios that differ between a combination of navigation systems and considering higher-order ionospheric delay corrections. The "only GPS" and "GPS+GLONASS+Galileo+BDS" observations data without/with eliminating ionospheric delay error of higher orders were processed in the static PPP, respectively. Table 1 shows the processing scenarios list. Here, the abbreviation G, R, E and C represent GPS, GLONASS, Galileo and BDS, respectively. The signs "I-" and "I+" represent the without and with eliminating ionospheric delay error of higher-order, respectively.

Table 1

Processing scenarios

\begin{tabular}{|l|l|l|}
\hline Scenario number & GNSS constellations & IONEX \\
\hline 1 & G & I- \\
\hline 2 & G $+\mathrm{R}+\mathrm{E}+\mathrm{C}$ & $\mathrm{I}-$ \\
\hline 3 & $\mathrm{G}$ & $\mathrm{I}+$ \\
\hline 4 & $\mathrm{G}+\mathrm{R}+\mathrm{E}+\mathrm{C}$ & $\mathrm{I}+$ \\
\hline
\end{tabular}

GipsyX was set to run in PPP mode (Zumberge et.al., 1997), with applied IERS2010 recommendations for the solid Earth tides model (Petit, Luzum, 2010) and FES2004 model for ocean tide loading (Lyard et.al., 2006). Antenna phase corrections and an elevation cut-off $7^{\circ}$ were also applied. For tropospheric modeling empirical model of Global Pressure and Temperature GPT2 (Lagler et.al., 2013) and Global Mapping Function GMF (Boehm et.al., 2006) were applied. The wet delay and gradient parameters were modeled as random walk variables with 5 and $0.5 \mathrm{~mm} / \mathrm{ph}$, as recommended by GipsyX manual pages. A priori wet delay was fixed to $100 \mathrm{~mm}$. Phase ambiguities were fixed using special res-function, which allows the constraint of double difference integer ambiguities using data from a single receiver, when using clock and orbital data. The products contain a file with wide-lane bias and phase bias information from the global network used to compute the bias fixed orbits and clocks. Detailed description on algorithm can be found in (Bertiger et.al., 2010, Savchuk et.al., 2020). As processing results, we received coordinates for every day of the GNSS station BOR1 for each scenarios. It allowed generalizing the obtained of coordinate changes velocity and their evaluation. Figure 1 shows the graphical representations of the fourth scenario processing results. On the left, we have the plot of observed and modeled position of the station (referenced to the epoch 2019.000), and on the right - residuals plot, that shows the difference between the observed and modeled positions. 

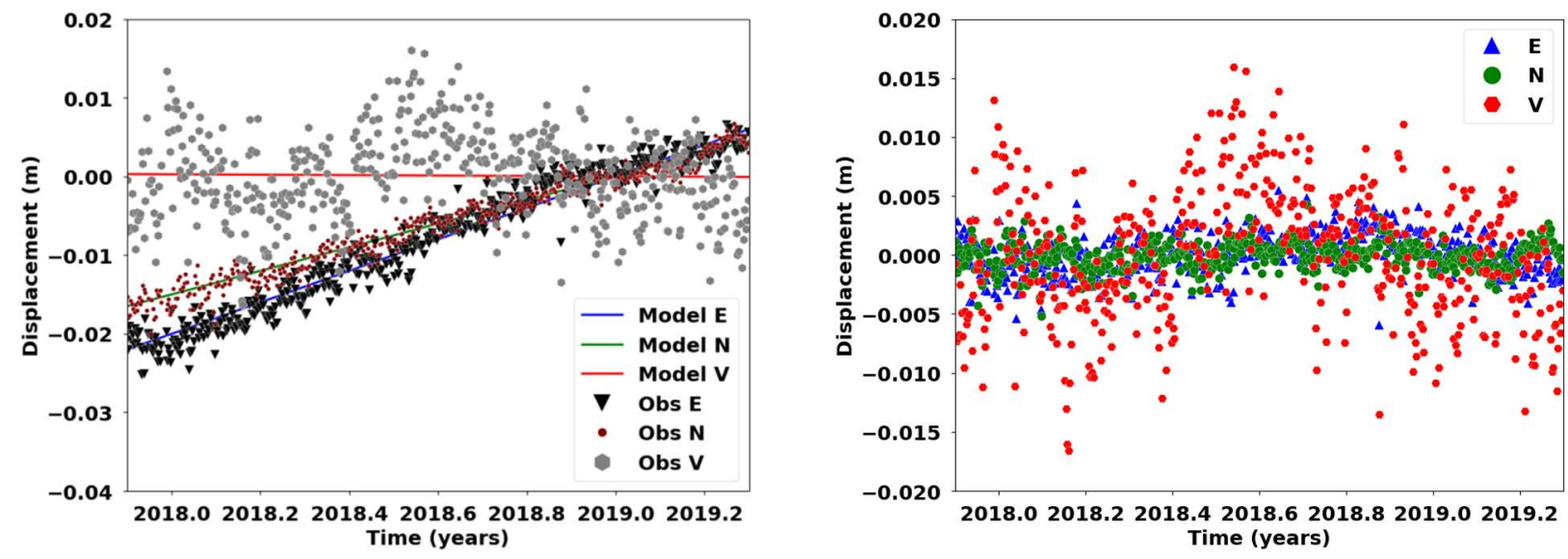

Fig. 1. Results of fourth processing scenario for the station BOR1

As the differences in the results of the processing under the four scenarios are almost not noticeable graphically, we compiled the results obtained into a Table 2, where STA are positions, VEL are velocities, REP - RMS error of coordinate repeatability of GNSS station BOR1 for a time series of observable period.

Table 2

Estimated parameters for the station BOR1

\begin{tabular}{|c|c|c|c|c|c|c|c|}
\hline \multirow{2}{*}{ Scenario } & \multirow{2}{*}{ Parameter } & \multicolumn{3}{|c|}{ Values } & \multicolumn{3}{|c|}{ Accuracy } \\
\hline & & E & $\mathrm{N}$ & V & $\mathrm{E}$ & $\mathrm{N}$ & V \\
\hline \multirow{3}{*}{1} & STA $[\mathrm{mm}]$ & 17.0735 & 52.2770 & 124.3592 & $63 \cdot 10^{-6}$ & $38 \cdot 10^{-6}$ & $106 \cdot 10^{-6}$ \\
\hline & VEL [mm/year] & 20.4056 & 14.6554 & -2.1287 & 0.089 & 0.054 & 0.151 \\
\hline & $R E P[\mathrm{~mm}]$ & 0.002 & 0.001 & 0.005 & & & \\
\hline \multirow{3}{*}{2} & STA [mm] & 17.0735 & 52.2770 & 124.3590 & $63 \cdot 10^{-6}$ & $38 \cdot 10^{-6}$ & $106 \cdot 10^{-6}$ \\
\hline & VEL [mm/year] & 20.4136 & 14.6644 & -2.1239 & 0.089 & 0.054 & 0.151 \\
\hline & $R E P[\mathrm{~mm}]$ & 0.002 & 0.001 & 0.005 & & & \\
\hline \multirow{3}{*}{3} & STA [mm] & 17.0735 & 52.2770 & 124.3609 & $35 \cdot 10^{-6}$ & $23 \cdot 10^{-6}$ & $66 \cdot 10^{-6}$ \\
\hline & VEL [mm/year] & 20.0022 & 14.9978 & -0.2532 & 0.051 & 0.033 & 0.096 \\
\hline & $R E P[\mathrm{~mm}]$ & 0.002 & 0.001 & 0.005 & & & \\
\hline \multirow{3}{*}{4} & STA [mm] & 17.0735 & 52.2770 & 124.3607 & $35 \cdot 10^{-6}$ & $23 \cdot 10^{-6}$ & $66 \cdot 10^{-6}$ \\
\hline & VEL [mm/year] & 20.0160 & 15.0090 & -0.2558 & 0.051 & 0.033 & 0.096 \\
\hline & $R E P[\mathrm{~mm}]$ & 0.002 & 0.001 & 0.005 & & & \\
\hline
\end{tabular}

According to this table, in the coordinate velocities domain we could noticed shifts between the two processing variants: a positive eastward and northward shifts (up to $10 \mathrm{~mm}$ ) and positive vertical shift (up to $2 \mathrm{~mm}$ ), when coordinate velocities obtained from the solution with I+ and the solution with I-. However, it is well demonstrated the dependence of the obtained results on the number of satellite systems used in the processing. The most significant is this dependence for the vertical component of coordinates. For example, in the situation with stations coordinates the horizontal components are equal for all scenarios, but the vertical components are different in $10 \mathrm{~mm}$ with scenarios 1,2 and 3, 4 . The results shown in Table 2, in general, indicate that different pairs of scenarios differ at the submillimeter level, but for high accuracy PPP, higher-order ionospheric delay must be taken into consideration.

\section{Conclusions and proposals}

In this paper the observations data from GNSS station BOR1 was processed using GipsyX in PPPmode software. It has been proven once again that this software package is a very powerful tool for processing GNSS observations data, including multi-GNSS. The higher-order ionospheric delay and its impact on the accuracy of multi-GNSS observations data processing were studied. It was evaluated the ionospheric correction by GIMs provided in IONEX files produced by CODE. The results also show that the multi-GNSS processing are better than those based on "only GPS". The results indicate 
that different pairs of scenarios (solution with I+ and the solution with I-) differ at the submillimeter level, and the basic assumption is that the selected observation period was carried out in a more quiet period when no fluctuations in the ionosphere were present. Therefore, further studies of this type are necessary, but a proposed strategy should be applied for dates when ionospheric fluctuations are present.

\section{References}

1. Bassiri S., Hajj G.A. (1993) Higher-order ionospheric effects on the GPS observables and means of modeling them, Adv Astronaut Sci, Volume 18, Issue 6, pp. 280-289.

2. Bertiger W., Desai S.D., Haines B., Harvey N., Moore A.W., Owen S., Weiss J.P. (2010) Single receiver phase ambiguity resolution with GPS data, Journal of Geodesy, Volume 84, Issue 5, pp. 327-337, doi:10.1007/s00190-010-0371-9.

3. Boehm J., Niell A., Tregoning P., Schuh H. (2006). Global Mapping Function (GMF): A new empirical mapping function based on numerical weather model data, Geophysical Research Letters, Volume 33, Issue 7. doi:10.1029/2005GL025546.

4. Elsobeiey M., El-Rabbany A. (2012) An efficient model for GPS precise point positioning, The 14th IAIN Congress.

5. Feltens J., Schaer S. (1998) IGS products for the ionosphere, Proceeding IGS Ac workshop, pp. 225-232.

6. Gu S., Shi C., Lou Y., Liu J. (2015) Ionospheric effects in uncalibrated phase delay estimation and ambiguity-fixed PPP based on raw observable model. J. Geod. Volume 89, pp. 447-457.

7. Hargreaves J. (1992) Principles of ionosphere. Cambridge University Press, Cambridge.

8. Lagler K., Schindelegger M., Böhm J., Krásná H., Nilsson T. (2013). GPT2: Empirical slant delay model for radio space geodetic techniques, Geophysical Research Letters, Volume 40, Issue 6, pp. 1069-1073, doi: $10.1002 / \mathrm{grl} .50288$

9. Lou Y., Zheng F., Gu S., Wang C., Guo H., Feng Y. (2016) Multi-GNSS precise point positioning with raw single-frequency and dual-frequency measurement models. GPS Solut., Volume 20, pp. 849-862.

10. Lyard F., Lefevre F., Letellier T., Francis O. (2006) Modelling the global ocean tides: modern insights from FES2004, Ocean Dynamics, Volume 56, pp. 394-415, doi:10.1007/s10236-006-0086-x.

11. Marques H.A., Monico J.F.G., Rosa G.P.S., Chuerubim M.L., Aquino Márcio (2012) Second and third order ionospheric effects on GNSS positioning: a case study in Brazil, Int Assoc Geodesy Symp, Volume 136, Issue 1, pp. 619-625.

12. Odijk D. (2003) Ionosphere-free phase combinations for modernized GPS. J. Surv. Eng., Volume 129, pp. $165-173$.

13. Official web-site of GIPSY-OASIS software package (GNSS-Inferred Positioning System and Orbit Analysis Simulation Software). Available online: https://gipsy-oasis.jpl.nasa.gov/.

14. Petit G., Luzum B. (2010) IERS conventions 2010, IERS Technical Note No. 36, (http://www.iers.org/IERS/EN/Publications/TechnicalNotes/tn36.htm).

15. Savchuk S., Khoptar A. (2019) Analysis of the tropospheric delay estimates in software package - GipsyX based on multi-GNSS observations, Modern achievements of geodesic science and industry, Volume 37, Issue 1, (http://zgt.com.ua/wp-content/uploads/2019/04/13.pdf).

16. Savchuk S., Khoptar A., Sosonka I. (2020) Processing of a regional network of GNSS stations by the PPP method, Wybrane aspekty zabezpieczenia nawigacji lotniczej, Część 2, Seria wydawnicza współczesna nawigacja, Tom II, (https://indd.adobe.com/view/8984c5bb-956b-4cad-bbce-afdaa8ca3267).

17. Schear S., Gurtner W., Feltens J. (1998) IONEX: the IONosphere map EXchange format version 1, IGS AC Workshop, Darmstadt, Germany .

18. Schaer S. (1999) Mapping and Predicting the Earth's Ionosphere Using the Global Positioning System. Ph.D. Thesis, Astronomical Institute, University of Berne, Bern, Switzerland.

19. Seeber G. (2008) Satellite Geodesy. Foundations, Methods, and Applications. Berlin, Boston: De Gruyter Gilbert Strang, Kai Borre: Linear Algebra, Geodesy, and GPS; Wellesley-Cambridge Press, ISBN 09614088-6-3.

20. The Multi-GNSS Experiment and Pilot Project (MGEX). Available online: http://mgex.igs.org.

21. Zumberge J., Heflin M., Jefferson D., Watkins, M., Webb F. (1997) Precise point positioning for the efficient and robust analysis of GPS data from large networks. Journal of Geophysical Research, Volume 102, Issue B3, pp. 5005-5017. doi:10.1029/96JB03860.

Information about authors:

Alina Khoptar, M.Sc., Ph.D. student, Lviv Polytechnic National University. 79013, Lviv, S. Bandera st., 12, alina.a.khoptar@lpnu.ua. Earth space monitoring.

Stepan Savchuk, Doctor of Engineering Science, Professor, Professor of the Institute of Geodesy, Lviv Polytechnic National University, Lviv, Ukraine, ssavchuk@polynet.lviv.ua. Geodesy, geodetic reference systems and frames, precise satellite positioning. 